\title{
NOSSA TERESA, DE MICHELINY VERUNSCHK, NÃO ESTÁ AQUI
}

Renan Augusto Ferreira Bolognin Doutorando em Estudos Literários pela Universidade Estadual Paulista

(Unesp/Araraquara)

renanbolognin@hotmail.com

Nicolas Ferreira Neves Jacintho

Graduando em Letras Português/Inglês pela Universidade Federal de São Carlos

(UFSCar)

nicolas.nevesf@gmail.com

\section{LIVRO RESENHADO}

VERUNSCHK, Micheliny. Nossa Teresa: vida e morte de uma santa suicida. São Paulo: Patuá, 2014. 188 p.

Temos gula de ver. Temos pressa de espiar. Somos de um tempo em que o olhar é o sentido predominante. Com ele queremos dar conta de possuir tudo, de tudo controlar (VERUNSCHK, 2014, p. 27).

O grande trunfo do romance Nossa Teresa - da autora estreante no gênero Micheliny Verunschk ${ }^{i}$ - é a construção de uma personagem inefável. Talvez como uma santa deva ser. A protagonista que se desvanece nas páginas do livro é uma garota induzida, por um padre de índole duvidosa, a cometer suicídio com a finalidade de converter-se na santa dos suicidas. Por isso, uma jornalista italiana parte no encalço de respostas sobre Teresa na cidade natal da garota. Longe de respostas definitivas, o avião em que a jornalista voltava a Roma sofre uma pane que o derruba no Atlântico: 
Dias depois, no avião, o sono quase tenso a sobressalta. O livro, a reportagem, uma sensação de tudo poder, que ela acha, vai se estender por anos a fio. Seu livro será um sucesso. E seu último pensamento. Depois, a explosão (VERUNSCHK, 2014, p. 111).

Não gratuitamente, Teresa é vista pela jornalista durante a queda do avião. Ou é isso que é contado de maneira plúmbea pelo narrador heterodiegético que se esconde sempre em torno de sua linguagem empolada e de sua (ao que nos pareceu) interlocução exagerada conosco, leitores. Isto é, uma estratégia narrativa (das mais irritantes, por vezes) que esconde primorosamente Teresa de nosso olhar contemporâneo viciado em ver com todas as cores. Por isso, nos perguntamos durante a leitura: onde está Teresa?

A esse respeito, cabe uma das passagens mais líricas do romance que evidencia a inefabilidade da santa: "De longe é uma pedra, um lagarto, uma ave. De longe, é um ponto, uma pedra, talvez uma árvore. De longe, pode ser tudo. De perto, é uma mulher" (VERUNSCHK, 2014, p. 43). Acercar-se de Teresa exige um sentimento próprio do religioso: o ato de fé. Deve-se pensar nela como próxima ao mistério de se crer, embora não se leia (ou veja) a personagem correndo pelas linhas do livro.

Se lermos assim, poderemos visualizar um grande paradoxo: como lidar com a fé e o mistério do invisível da tradição religiosa católica neste período histórico em que vivemos ancorados em imagens? Sobre isso, o romance apresenta o momento imagético em que vivemos entrelaçado aos simulacros (da presença de um objeto no lugar da ausência do santo cultuado), tão caros a Jean Baudrillard (1981). Logo, não nos espanta que a via de acesso ao mundo místico na vida e nessa ficção seja dada mediante a imagem: 
Em êxtase, Teresa passava a mão pelo lado interno de uma vidraça da sala de aula e, do contato entre sua mão suada e o vidro, celestiais apareciam: a Virgem, o próprio Cristo, figuras angelicais. Muitos puderam ver. Muitos puderam comprovar. E o que todos repetem, a circularidade da fé (VERUNSCHK, 2014, p. 116).

Teresa em êxtase, envolta em "jaculações místicas" (LACAN, 1985, p. 103), dissolve a dicotomia entre corpo e espírito, o que se acentua quando pensamos na presença de símbolos que evocam o paganismo ao longo do romance, esboroando a distância entre o físico e o transcendente e colocando o suicídio de Teresa como ato necessário para chegar à santidade.

Pensar a Teresa de Verunschk é, muitas vezes, evocar a escultura de Bernini, $A$ transverberação de Santa Teresa (1645-1652), em que o artista italiano representou o êxtase da experiência mística de Santa Teresa de Ávila ao ser atingida pela flecha empunhada por um anjo. Em ambos os casos, na escultura e no romance, estamos diante de uma representação que fica no limiar entre o físico e o transcendente, entre o corpo e o espírito.

Há ainda, entre várias outras dicotomias, a do conhecimento sacro popular e do erudito, uma vez que o livro põe em xeque a formação intelectual religiosa dicotômica pela qual passamos. Com requintes de ironia, a beatificação de Teresa é localizada entre o senso comum e o conhecimento profundo do tema. Aliando essa discussão à presença de imagens no livro, notamos que em Nossa Teresa há uma discussão implícita a respeito da(s) verdade(s) mística(s) associada(s) a esses simulacros.

No bojo dessas imagens entrelaçam-se outras dicotomias inerentes à nossa formação cultural, como santidade masculina e demonismo feminino. Como sabemos, no catolicismo, a mulher sempre esteve associada à bruxaria sendo, por isso, deslocada para 
o polo negativo do conhecimento místico. Porém, Teresa associa-se à santidade ao recuperar e incorporar implicitamente Maria e suas infinitas formas, "Nossa senhora de...", "Santa" e "Virgem...", através das adjetivações na oração presente no final do livro: "Nossa Senhora do Crack", "Santa Felisbina Müller", "Santa Maria Degolada" e "Santa Teresa Suicida" (VERUNSCHK, 2014, p. 187-188).

Entre a grande falange abrangida pela santa (e demônio também), está a dos suicidas, o que gera outro entrechoque dicotômico entre o físico e o espiritual: do corpo e da alma entregues por Deus e que se balançam à vontade humana, ao livre arbítrio, em contraponto às leis divinas. Assassínio próprio, pecado outorgado pela Igreja ao praticante, desembocando no umbral da dicotomia: a santidade chega a uma de suas realizadoras. Ou não?

À dicotomia santidade/demonismo entrelaça-se a percepção da cultura católica à do Outro. Por isso, o tido como responsável pelo acidente aéreo é um muçulmano. Não à toa, as ilustrações da capa, feitas por Leonardo Mathias, aliam-se às nossas percepções religiosas. Estamos diante de uma dicotomia de santificação/demonização associada ao nosso olhar cultural por vezes predominantemente cristão sem que o saibamos. Por isso, o movimento da narrativa coloca a santificação dessa Teresa inefável no entre-lugar da morte e da vida, do catolicismo e do paganismo.

Na capa, há entidades católicas, de tradição religiosa africana e do Oriente Médio que foram sincretizadas ou rechaçadas pela Igreja. Encontramos, então, da esquerda para a direita na capa: a morte, como símbolo da narrativa e relacionada à Teresa; um demônio de nome desconhecido que se liga à tensão entre o bem e o mal por que passa Teresa; o Sagrado Coração de Jesus substituído por um cálice, que representa a feminilidade e sua santificação no catolicismo; um homem tapando os olhos enquanto 
uma criança agoniza a seus pés como símbolo do suicídio da menina provocado pelo padre; uma entidade que possui características de Baphomet, Belzebu e Satanás, reverberando os domínios dos trêsii durante a narrativa; uma menina com um vestido e uma auréola remetendo a Teresa; e Oxum olhando em seu espelho e recordando a importância fulcral da imagem neste romance ${ }^{\text {iii }}$.

Figura 1 - Capa do livro Nossa Teresa

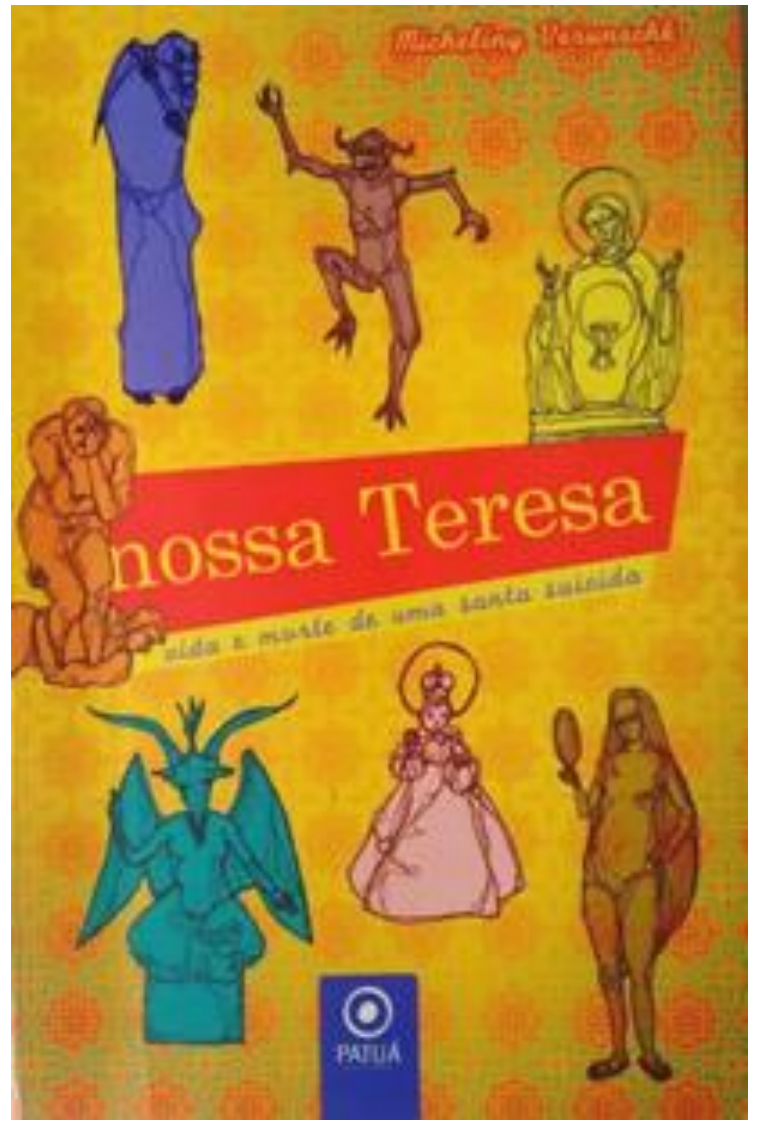

Fonte: Disponível em:

<http://www.anobii.com/books/Nossa_Teresa/9788582971215/01175ae37a89a6a21a>.

Finalizando a leitura do livro, talvez, a única nódoa restante como segura em meio a tantas dicotomias constituintes do desaparecimento de Teresa é a marca de sua "morte por nós" e que a fez multiplicar-se em estilhaços postos frente a frente pelo narrador. Algo similar ao escrito no colofão do livro pela autora: “Em 2004, a história de uma 
menina chamada Teresa chegou até mim. Teresa se transformou em outras, se multiplicou. É um nome. Um amuleto: Teresa, a colheita do verão daquele ano" (VERUNSCHK, 2014, p. 192).

Se o leitor tiver dificuldade de encontrar Teresa no romance, saiba que ela também não está nesta resenha. Sua multiplicação em muitas é seu artifício narrativo. O único caminho possível para encontrá-la incorporada é a devoção religiosa: ter fé em sua existência.

\section{Referências}

BAUDRILLARD, Jean. Simulacros e simulações. Tradução de Maria João da Costa Pereira. Lisboa, Portugal: Éditions Galilée, 1981.

BERNINI, Gian Lorenzo. A transverberação de Santa Teresa. Título original: La transverberazione di Santa Teresa. 1647-1652. Escultura em mármore branco. [Roma, Itália: Igreja Santa Maria della Vittoria].

LACAN, Jacques. O seminário: Livro 20. Tradução de M. D. Magno. Rio de Janeiro: Jorge Zahar Editor, 1985.

LEVI, Eliphas. Dogmas e ritual da alta magia. Tradução de Rosabis Camaysar. São Paulo: Pensamento, 1993.

VERUNSCHK, Micheliny. Nossa Teresa: vida e morte de uma santa suicida. São Paulo: Patuá, 2014.

\footnotetext{
'As primeiras publicações de Micheliny Verunschk e que a consagraram foram os livros de poesia, Geografia íntima do deserto (2003), finalista do prêmio Portugal Telecom 2004, e A cartografia da noite (2010) entre outros. Com Nossa Teresa, Verunschk ganhou o prêmio São Paulo de Literatura 2015, na categoria de melhor romance de autor estreante acima de 40 anos.
} 


\footnotetext{
ii A representação de Baphomet utilizada na capa do romance lembra a criada por Eliphas Levi no século XIX e traz em si a ambiguidade representada pela entidade: as dicotomias entre o espiritual e o carnal, o bem e o mal, o masculino e o feminino, o humano e o animal; Belzebu, uma das entidades cujas características podem ser vistas na imagem da capa do romance, era cultuado originalmente nas regiões da Filisteia e da Cananeia, sendo conhecido como deus da meteorologia e de tudo o que voa, daí o seu nome ser por vezes traduzido como "Senhor das moscas" - no romance, sua influência é observada no acidente aéreo por que passa a jornalista italiana; há, finalmente, Satanás, deus sumério associado à encarnação do mal em religiões monoteístas, como é o caso do cristianismo.

iii Há ainda, no livro, uma imagem que pode ser associada à lansã, deusa africana dos ventos e tempestades.
}

Recebido em 21 de janeiro de 2018.

Aceito em 8 de março de 2018. 